\title{
Intradural cyst: intramedullary or extramedullary? Illustrative case
}

\author{
Timothy Kim, BS, Brendan Judy, MD, and Timothy Witham, MD \\ Department of Neurosurgery, Johns Hopkins Hospital, Baltimore, Maryland
}

BACKGROUND Intradural spinal cord cysts are uncommon and generally benign. It can be difficult to determine whether the cyst is intramedullary or extramedullary on preoperative imaging, and the location of the cyst may be determined intraoperatively. This patient presented with intractable back pain associated with imbalance and was found to have a cystic lesion of the ventriculus terminalis (VT).

OBSERVATIONS The patient was found to have a cystic lesion of the VT that was intramedullary rather than extramedullary, as initially expected based on preoperative imaging.

LESSONS VT is a rare cystic expansion of the conus medullaris that can appear extramedullary on preoperative imaging. Intraoperatively, this lesion was found to be intramedullary and was successfully treated with fenestration.

https://thejns.org/doi/abs/10.3171/CASE21327

KEYWORDS spinal cord cyst; back pain; intramedullary cyst; extramedullary cyst

The purpose of this study is to present a case of ventriculus terminalis (VT) that appeared extramedullary on preoperative imaging but, intraoperatively, was determined to be intramedullary. VT is a rare cause of neurological deficit and may be effectively treated with myelotomy and fenestration.

\section{Illustrative Case}

A 54-year-old woman presented with a chief complaint of intractable lower thoracic pain associated with imbalance. This was preceded by 2 years of back pain after a fall, resulting in complex regional pain syndrome of her left foot. She was treated with multiple nerve blocks; however, following a nerve block, she developed left foot drop and decreased sensation throughout her left foot and subsequently decreased sensation in her right foot. Over the past several months, her imbalance worsened, and the frequency of her falls increased. She developed muscle spasms affecting both lower extremities. She had no bowel or bladder dysfunction and denied any upper extremity signs or symptoms. Her neurological exam was notable for left dorsiflexion weakness ( 2 of 5 ), left eversion weakness ( 3 of 5 ), and decreased bilateral patellar and Achilles reflexes. Electromyography revealed left $\mathrm{L} 5$ nerve changes with absent $\mathrm{F}$ wave in the common peroneal nerve without signs of peripheral neuropathy. Magnetic resonance imaging (MRI) of the lumbar spine demonstrated a cystic lesion near the conus medullaris at T11-12 that appeared to be intradural and extramedullary (Fig. 1). Given her symptoms, the patient underwent surgery. A thoracic laminoplasty (T11-12) was performed, and after durotomy, tethered spinal cord was encountered. After detethering the spinal cord, the conus medullaris was noted to be markedly expanded. Visual inspection and ultrasound revealed the cystic lesion to be intramedullary rather than extramedullary (Fig. 2). Therefore, a myelotomy and fenestration were performed to decompress the cyst. The spinal cord became less swollen in appearance and more pulsatile. The dura was closed primarily. The patient tolerated the procedure well and immediately noted significant pain relief in her lower back and extremities, as well as improved sensation. At 1 month follow-up, these improvements were durable, and the patient was recovering well.

\section{Discussion \\ Observations}

Intradural spinal cord cysts are overall benign and rare. ${ }^{1,2} \mathrm{~A}$ variety of intradural cysts exist, including arachnoid, bronchogenic, colloid, ependymal, epithelial, foregut, neurenteric, and teratomatous cysts. ${ }^{1} \mathrm{MRI}$ is the

ABBREVIATIONS CLVT = cystic lesion of the ventriculus terminalis; MRI = magnetic resonance imaging; VT = ventriculus terminalis. INCLUDE WHEN CITING Published July 19, 2021; DOI: 10.3171/CASE21327.

SUBMITTED May 26, 2021. ACCEPTED May 28, 2021.

(c) 2021 The authors, CC BY-NC-ND 4.0 (http://creativecommons.org/licenses/by-nc-nd/4.0/). 

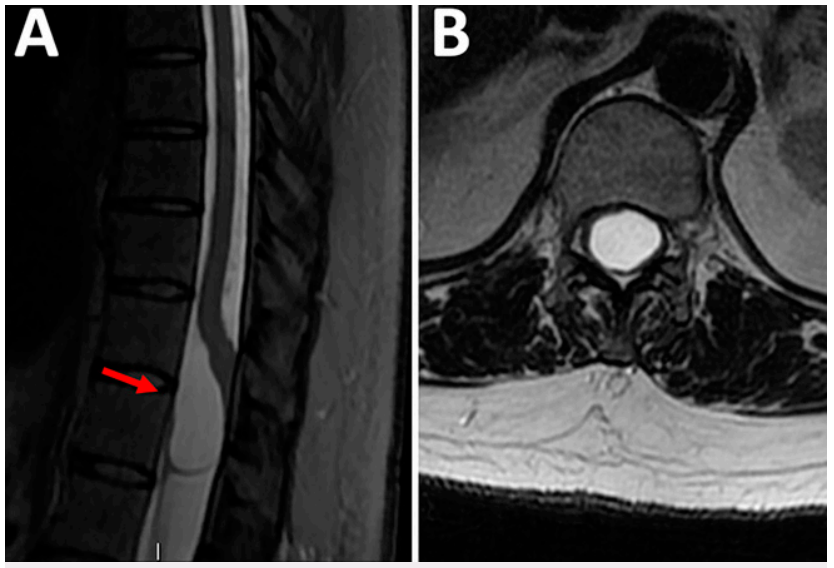

FIG. 1. Intradural cyst. Thoracic spine MRI: T2-weighted sagittal view (A) shows an intradural cystic lesion seemingly ventral to the conus (red arrow). T2-weighted axial view (B) at the level of maximal cyst diameter shows intradural cyst occupying the entirety of the spinal canal.

best imaging modality for evaluation. ${ }^{1}$ Location of the cyst in relation to the dura (intradural or extradural) and spinal cord (intramedullary or extramedullary) may be characterized with imaging. However, in this case, while the MRI suggested that the cyst was extramedullary, it was found to be intramedullary. Given the location of the cyst and the imaging findings, this lesion was a cystic lesion of the VT (CLVT). VT, or the fifth ventricle, is an ependymal-lined cavity filled with cerebrospinal fluid found in the conus medullaris. ${ }^{3}$ Normally, VT is present in all patients during fetal development and regresses completely by early childhood. ${ }^{3}$ In rare cases, a residual ventricular cyst may remain into adulthood and enlarge to give rise to neurological symptoms. Symptoms may include low-back pain, lower extremity pain, focal neurological deficit, altered deep tendon reflexes, and urological dysfunction. ${ }^{4}$ The physiological role of the VT is undetermined, and its pathogenesis is unclear. ${ }^{4}$

\section{Lessons}

In summary, this is a rare case of CLVT that appeared extramedullary on imaging but was noted to be an intramedullary lesion. There are obvious limitations, given that this is a single case report. However, it is an important lesson to remember that preoperative imaging is not definitive and that intraoperative decision-making may be necessary for
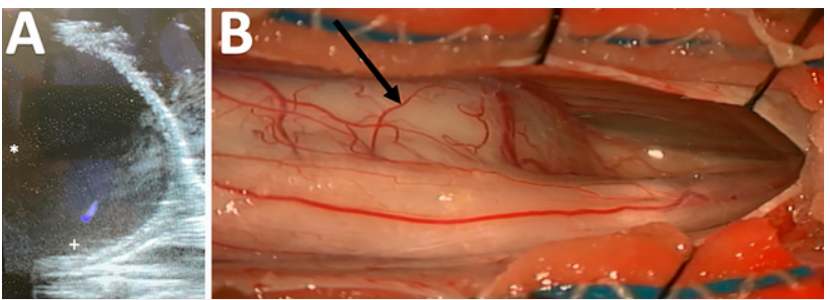

FIG. 2. Intraoperative view of cyst. A: Intraoperative ultrasound demonstrating intramedullary cyst. The asterisk demonstrates rostral, and the plus symbol indicates ventral. B: Intraoperative microscopic view of VT indicated by black arrow.

successful patient outcome. Finally, fenestration of CLVT is an effective treatment that leads to neurological improvement and decreased pain.

\section{References}

1. Park CH, Hyun S-J, Kim K-J, Kim H-J. Spinal intramedullary ependymal cysts: a case report and review of the literature. J Korean Neurosurg Soc. 2012;52(1):67-70.

2. Domingo RA, Bohnen AM, Middlebrooks EH, et al. T10-L3 cystic lesion of the ventriculus terminalis presenting as conus medullaris syndrome. World Neurosurg. 2020;136:146-149.

3. Van Rillaer O, Vandaele P, Ramboer K. Malformative persistence of terminal ventricle. JBR-BTR. 2009;92(3):178-179.

4. Ganau M, Talacchi A, Cecchi PC, et al. Cystic dilation of the ventriculus terminalis. J Neurosurg Spine. 2012;17(1):86-92.

\section{Disclosures}

Dr. Witham reported other from Augmedics Inc and Addivation Medical, personal fees from Depuy/Synthes, and grants from Gordon and Marilyn Macklin Foundation outside the submitted work.

\section{Author Contributions}

Conception and design: all authors. Acquisition of data: all authors. Analysis and interpretation of data: all authors. Drafting the article: Kim, Judy. Critically revising the article: all authors. Reviewed submitted version of manuscript: all authors. Approved the final version of the manuscript on behalf of all authors: Witham. Study supervision: Witham.

\section{Correspondence}

Timothy Witham: Johns Hopkins University School of Medicine, Baltimore, MD. twitham2@jhmi.edu. 